JOÃO DE SOUZA ALHO NETO

\title{
INTERPRETAÇÃO LITERAL E BENEFÍCIOS FISCAIS NO DIREITO TRIBUTÁRIO BRASILEIRO
}

Dissertação de Mestrado

Orientador: Professor Titular Dr. Humberto Bergmann Ávila

UNIVERSIDADE DE SÃO PAULO

FACULDADE DE DIREITO

SÃO PAULO-SP

2020 

JOÃO DE SOUZA ALHO NETO

INTERPRETAÇÃO LITERAL E BENEFÍCIOS FISCAIS NO DIREITO TRIBUTÁRIO BRASILEIRO

Dissertação apresentada à Banca Examinadora do Programa de Pós-Graduação em Direito, da Faculdade de Direito da Universidade de São Paulo, como exigência parcial para obtenção do título de Mestre em Direito, na área de concentração Direito Econômico, Financeiro e Tributário, sob a orientação do Professor Titular Dr. Humberto Bergmann Ávila.

UNIVERSIDADE DE SÃO PAULO

FACULDADE DE DIREITO

SÃO PAULO-SP 
Autorizo a reprodução e divulgação parcial deste trabalho, por qualquer meio convencional ou eletrônico, para fins de estudo e pesquisa, desde que citada a fonte.

\title{
Serviço de Biblioteca e Documentação
}

\section{Faculdade de Direito da Universidade de São Paulo}

São Paulo - 2020

\begin{abstract}
ALHO NETO, João de Souza.
Interpretação literal e benefícios fiscais no Direito Tributário brasileiro. 160 p.

Orientador: Professor Titular Dr. Humberto Bergmann Ávila

Dissertação (Mestrado), Universidade de São Paulo, USP, Programa de PósGraduação em Direito, 2020.

1. Benefício fiscal. 2. Interpretação literal. 3. Interpretação teleológica. 4. Princípio da igualdade. 5. Princípio da legalidade. 6. Princípio da segurança jurídica.
\end{abstract}


Nome: João de Souza Alho Neto

Título: Interpretação Literal e Benefícios Fiscais no Direito Tributário Brasileiro

Dissertação apresentada à Banca Examinadora do Programa de Pós-Graduação em Direito, da Faculdade de Direito da Universidade de São Paulo, como exigência parcial para obtenção do título de Mestre em Direito, na área de concentração Direito Econômico, Financeiro e Tributário.

Banca realizada em:

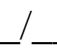

Resultado:

Banca Examinadora

Prof.(a) Dr.(a):

Instituição:

Julgamento: Assinatura:

Prof.(a) Dr.(a): Instituição:

Julgamento: Assinatura:

Prof.(a) Dr.(a): Instituição:

Julgamento: Assinatura: 

Aos meus pais. 



\section{AGRADECIMENTOS}

Embora seja exigido do candidato muita dedicação e horas de estudo para elaboração de um trabalho acadêmico, as conquistas almejadas por ele transcendem a sua pessoa. Elas devem ser compartilhadas com todos aqueles que, direta ou indiretamente, contribuíram para o sucesso do trabalho. Sendo assim, não poderia deixar de agradecer a todas as pessoas que, de alguma forma, me ajudaram a realizar o sonho de cursar o programa de pós-graduação da quase bicentenária Faculdade de Direito da Universidade de São Paulo.

Em primeiro lugar, agradeço ao Professor Humberto Ávila, exemplo de dedicação acadêmica, que me concedeu a oportunidade de ser um de seus orientandos. A orientação do Professor Humberto cuida, a um só tempo, do rigor acadêmico à altura da prestigiada Faculdade de Direito da Universidade de São Paulo, e da liberdade acadêmica, sendo uma de suas marcas a total independência do orientando para desenvolver suas próprias ideias. $\mathrm{O}$ Professor Humberto não se incomoda com a dissonância de pensamento, mas exige de seus orientandos argumentação robusta para sustentar suas conclusões.

Em segundo lugar, agradeço aos Professores que participaram de minha trajetória acadêmica até este momento, sem os quais a realização de um trabalho científico seria impossível. Agradeço, em especial, ao Professor Fernando Facury Scaff, que foi meu orientador de trabalho de conclusão de curso na Faculdade de Direito da Universidade Federal do Pará, e que em nossos encontros me entusiasma a seguir com as investigações acadêmicas. E, também, ao Professor Eurico de Santi, com quem tive o privilégio de trabalhar no Núcleo de Estudos Fiscais da Escola de Direito de São Paulo da Fundação Getulio Vargas, período em que me foi ensinado que a análise do Direito deve ser empírica e conectada com a realidade, com o objetivo sempre de melhorar o Brasil.

Em terceiro lugar, agradeço à minha família, em especial aos meus pais, Ney e Maria Clara, e aos meus irmãos, Clara Beatriz e Mário Henrique. Sem o apoio incondicional deles eu não teria superado os vários obstáculos que a vida me impôs. Desde muito cedo precisei me afastar de casa para perseguir meus sonhos, mas em nenhum momento senti a ausência desses entes queridos, que se fizeram presentes das mais variadas formas, me dando o conforto e o suporte necessário para seguir em frente. Agradeço, também, aos meus avós paternos, Mário e Beatriz, e maternos, João e Déa, que durante a vida se tornaram fontes de inspiração para mim. 
Em quarto lugar, agradeço aos meus queridos amigos, de todas as cidades que passei e de todas as instituições nas quais tive o prazer de estudar. Agradeço aos amigos da Universidade Federal do Pará, nas pessoas do André Pessôa, Andrei Maia, Beatriz Abtibol, Fernanda Barata, Giovanni Panatto, Laís Porto, Lucas Monte Santo, Luna Gorayeb, Mário Ribeiro e Talita Rossy; do Instituto Brasileiro de Direito Tributário, nas pessoas do Arthur Pitman, Fernando Bernardes, Jaime Araújo, João Batista, Mariana Guedes, Michel Przepiorka, Paulo Kimak e Pedro Jacob; da FGV Direito SP, nas pessoas do Gabriel Cypriano, Isaías Coelho e Lina Santin; e da Universidade de São Paulo, nas pessoas do André Coelho, Daniela Dias, Eduardo Halperin, Francisco Mileo, Jules Queiroz, Larissa Rocha, Maysa Pittondo, Paulo Arthur Koury, Pedro Ribas, Rodolfo Gil, Tadeu Puretz, Thaís Chanes e Túlio Terceiro.

Em quinto lugar, agradeço aos meus amigos Bruno Fulginiti, Francisco Mileo e Martha Leão, que leram detidamente este trabalho e ofertaram valiosas considerações. E, também, aos amigos Daniela Dias e Eduardo Halperin, com quem compartilhei algumas das minhas inquietações na construção de meus argumentos. Os eventuais êxitos desse trabalho são frutos dessas considerações e dessas conversas, por isso os compartilho com esses atenciosos amigos.

Em sexto lugar, agradeço aos servidores de todas as instituições que estive vinculado, em especial aos bibliotecários, o que faço na pessoa da Eloíza Pereira, do IBDT. Esses cuidadosos funcionários me ajudaram a realizar as pesquisas acadêmicas e nunca pouparam esforços para melhorar o ambiente de estudos.

A todos vocês, meu muito obrigado. 


\section{RESUMO}

ALHO NETO, João de Souza. Interpretação literal e benefícios fiscais no Direito Tributário brasileiro. 160 p. Dissertação de Mestrado - Faculdade de Direito, Universidade de São Paulo, São Paulo, 2020.

Este trabalho tem por objetivo responder a seguinte indagação: como devem ser interpretados os dispositivos relativos a benefícios fiscais no Direito Tributário brasileiro? Para tanto, será analisado, de um lado, o conteúdo prescritivo do artigo 111 do Código Tributário Nacional, que utiliza a expressão “interpreta-se literalmente”, e de outro lado, as funções eficaciais exercidas pelos princípios da igualdade, da legalidade e da segurança jurídica relativamente aos benefícios fiscais. Na primeira parte do trabalho, investigam-se as definições de "interpretação literal" e de "benefício fiscal", na medida em que contribuem tanto para a delimitação do conteúdo prescritivo do artigo 111 do CTN, quanto para a identificação dos dispositivos para os quais serão aplicados os critérios de interpretação que o trabalho sustenta serem os mais adequados. Em seguida, na segunda parte do trabalho, investigam-se quais são efetivamente esses critérios, o que é feito, primeiro, pela análise das diretivas interpretativas aplicáveis ao Direito Tributário em geral; segundo, pela delimitação do conteúdo prescritivo do artigo 111 do CTN e pela determinação dos parâmetros interpretativos aplicáveis aos dispositivos relativos a benefícios fiscais; e terceiro, pela aplicação desses parâmetros para casos difíceis, nos quais haverá entrechoque dos diferentes resultados interpretativos, sobretudo entre literalidade e teleologia da norma de desoneração. Por fim, o trabalho chegará à conclusão de que os dispositivos relativos a benefícios fiscais devem ser interpretados com base na finalidade constitucional que lhes é subjacente, por força do princípio da igualdade, devendo a teleologia da norma prevalecer sobre um eventual resultado literal que contemple um número menor de situações. O trabalho também concluirá que há vedação à integração analógica dessas normas por força do princípio da legalidade, e que, nos casos em que a literalidade for mais ampla que a teleologia, esta última cede prevalência à primeira por força do princípio da segurança jurídica.

Palavras-chave: interpretação literal; benefício fiscal; interpretação teleológica; igualdade; segurança jurídica. 



\begin{abstract}
ALHO NETO, João de Souza. Literal interpretation and tax benefits in Brazilian Tax Law. 160 p. Master's thesis - Faculty of Law, University of São Paulo, São Paulo, 2020.

This work aims to answer the following question: How should the provisions regarding tax benefits in Brazilian Tax Law be interpreted? In order to accomplish this goal, the work analyzes, on one hand, the prescriptive content of Article 111 of the Brazilian Tax Code, which uses the expression "literally interpreted", and on the other hand, the effective functions exercised by the principles of equality, legality and certainty in law regarding tax benefits. The first part of the work investigates the definitions of "literal interpretation" and "tax benefit", as they contribute to the delimitation of the prescriptive content of article 111 of the Brazilian Tax Code, as well as to the identification of the statutes for which the interpretation criteria that the work claims are the most appropriate will apply. The second part of the work investigates what these criteria really are, by, first, analyzing the interpretative directives applicable to Tax Law in general; second, by delimiting the prescriptive content of article 111 of the Brazilian Tax Code and by determining the interpretative parameters applicable to the tax benefit provisions; and third, by applying these parameters to hard cases, in which there will be clashing of the different interpretative results, especially between literality and teleology of the exemption rule. Finally, the work concludes that the provisions on tax benefits must be interpreted on the basis of the underlying constitutional purpose, by virtue of the principle of equality, and the teleology of the rule should take precedence over any literal outcome that includes a smaller number of situations. The work will further conclude that there is a prohibition on the analogical integration of these norms by virtue of the principle of legality, and that, where the literal meaning is broader than teleology, the latter gives way to the former by virtue of the principle of certainty in law.
\end{abstract}

Keywords: literal interpretation; tax benefit; teleological interpretation; equality; certainty in law. 



\section{SUMÁRIO}

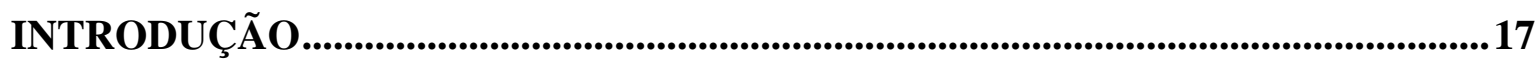

\section{PRIMEIRA PARTE \\ INTERPRETAÇÃO LITERAL E BENEFÍCIOS FISCAIS DEFINIDOS}

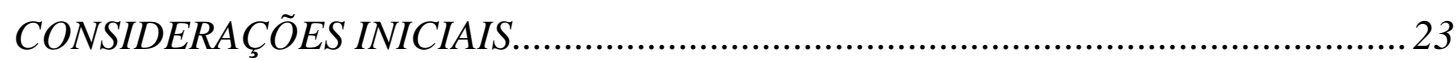

CAPÍTULO I: INTERPRETAÇÃO LITERAL (OU O QUE É INTERPRETAÇÃO LITERAL?).. 29

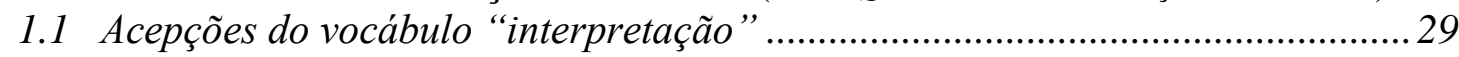

1.1.1 Interpretação como atividade ou processo............................................... 30

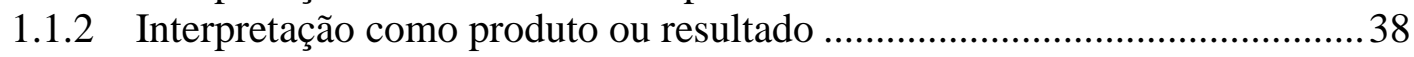

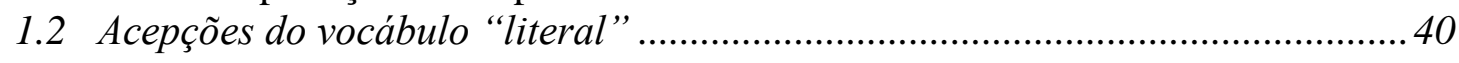

1.2.1 Literalidade na filosofia da linguagem ................................................. 41

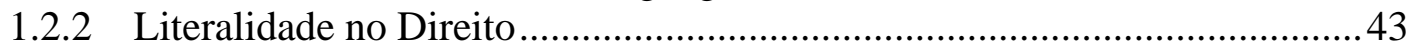

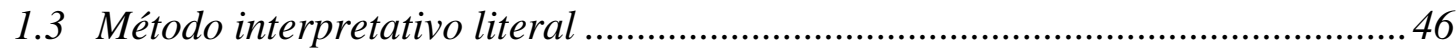

1.4 Interpretação literal e interpretações restritiva, extensiva e estrita ..................... 49

CAPÍTULO II: BENEFÍCIOS FISCAIS (OU O QUE SÃO BENEFÍCIOS FISCAIS?)..................55

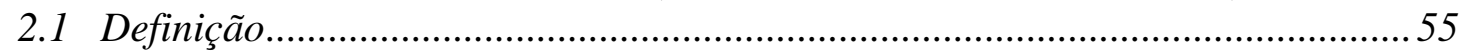

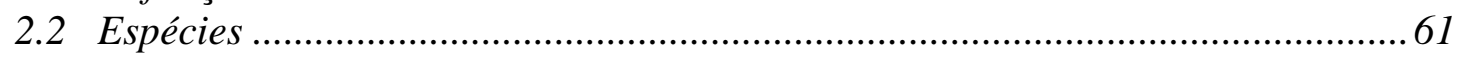

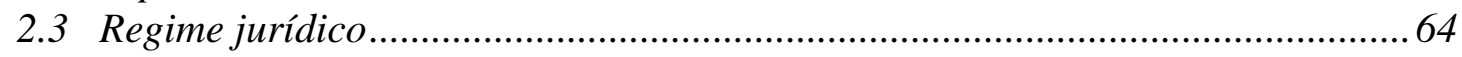

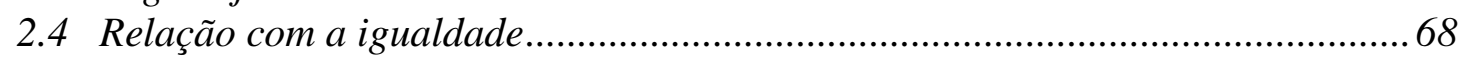

\section{SEGUNDA PARTE \\ INTERPRETAÇÃO DOS BENEFÍCIOS FISCAIS}

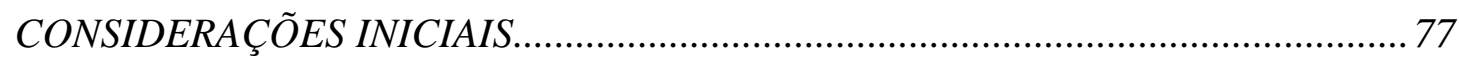

CAPÍTULO III: INTERPRETAÇÃO NO DIREITO TRIBUTÁRIO (OU COMO SE

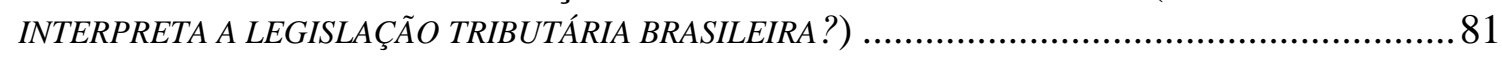

3.1 Direito Tributário e interpretação................................................................ 81

3.2 Atividade interpretativa tributária............................................................... 83

3.3 Resultado interpretativo tributário................................................................... 92

CAPÍTULO IV: O ARTIGO 111 DO CÓDIGO TRIBUTÁRIO NACIONAL (OU QUALO

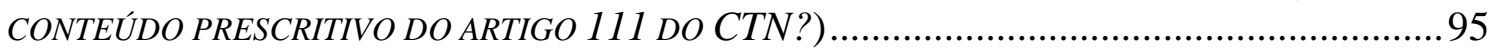

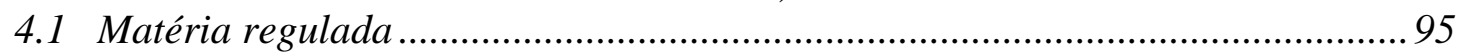

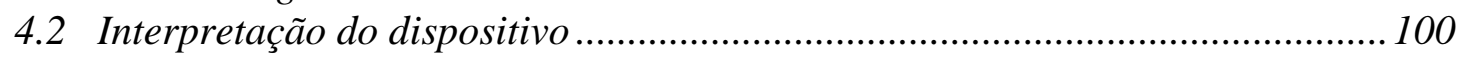

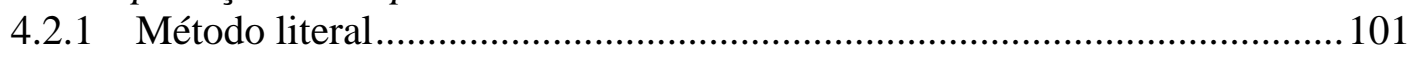

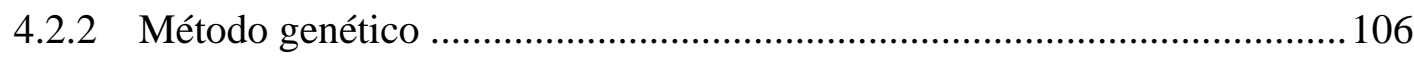

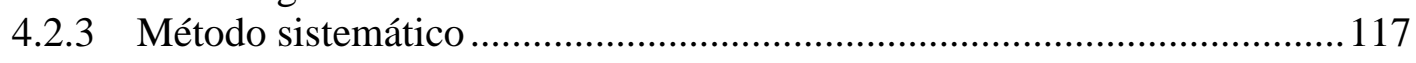


CAPÍTULO V: APLICAÇÃO DE NORMAS RELATIVAS A BENEFÍCIOS FISCAIS

(OU QUAIS OS CRITÉRIOS E LIMITES DO APLICADOR DE NORMAS RELATIVAS A BENEFÍCIOS

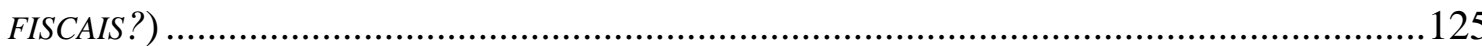

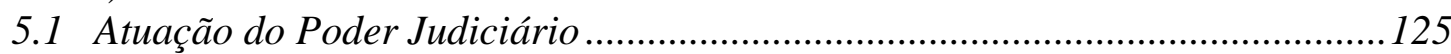

5.2 Casos difíceis ...................................................................................... 128

5.2.1 Situação fática fora da literalidade e dentro da teleologia da norma .........131

5.2.2 Situação fática dentro da literalidade e fora da teleologia da norma ..........136

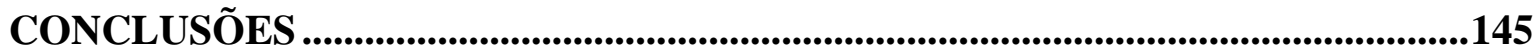

REFERÊNCIAS BIBLIOGRÁFICAS ..................................................................151 


\section{INTRODUÇÃO}

Como devem ser interpretados os dispositivos que tratam de benefícios fiscais? Embora pareça um questionamento trivial, sua resposta depende da análise de uma série de elementos do ordenamento jurídico. De um lado, o artigo 111 do Código Tributário Nacional, publicado em 1966, utiliza a expressão "interpreta-se literalmente" e tem seu conteúdo direcionado à fixação de critérios de interpretação para esses dispositivos; e de outro lado, a Constituição Federal de 1988, foi minuciosa no trato da matéria tributária, prevendo princípios que estabelecem direitos e garantias aos contribuintes e que também influem na interpretação desses dispositivos. A interpretação prima facie do artigo 111 e da Constituição leva a uma possível incongruência entre o conteúdo prescritivo do Código, que parece se limitar à interpretação literal, e o da Constituição, que parece oferecer uma perspectiva mais ampla, privilegiando ideais como igualdade, legalidade e segurança jurídica. Têm-se, portanto, normas distintas, reconstruídas a partir de diplomas normativos idealizados em épocas diferentes, mas que se aplicam à disciplina de uma mesma matéria. Assim, o objeto central do presente estudo é investigar a maneira pela qual estas normas se compatibilizam, de modo a determinar os parâmetros adequados de interpretação de dispositivos relativos a benefícios fiscais.

As divergências interpretativas acerca desses dispositivos assentam bases na concepção que se tinha e na que se tem hoje sobre o que é um benefício fiscal. Até meados do século passado, era assente na doutrina a ideia de que ramos jurídicos que tratam diretamente da relação do indivíduo com seus direitos fundamentais, sobretudo disciplinando hipóteses de limitação desses direitos, seriam "legislações odiosas", cujo campo de aplicação deveria ser o menor possível (odiosa sunt restringenda). ${ }^{1}$ Com base nessa premissa, a interpretação dos dispositivos relativos ao Direito Penal e ao Direito Tributário, por exemplo, seguiriam o adágio exceptio est strictissimae interpretationis, ${ }^{2}$ cujo significado remete à concepção de que as exceções devem ser interpretadas estritamente, obrigando que o intérprete se atenha ao texto da lei, sem se estender além ou se restringir aquém do disposto pelo legislador.

\footnotetext{
${ }^{1}$ VANONI, Ezio. Natureza e interpretação das leis tributárias. Trad. Rubens Gomes de Sousa. Rio de Janeiro: Edições Financeiras, 1932, p. 184.

${ }^{2}$ LEBEAU, Martin. De l'interprétation stricte des lois: essai de méthodologie. Paris: Defrénois Lextenso, 2012, p. 54
} 
Desta compreensão geral que se tinha a respeito do Direito Tributário, decorria que os benefícios fiscais eram verdadeiros favores ou privilégios conferidos pelo Estado ao particular. Os benefícios fiscais eram entendidos como benesses a serem concedidas a determinados indivíduos ao alvedrio do detentor do poder, quase que em relação "soberanovassalo". ${ }^{3}$ A noção de que os benefícios fiscais são liberalidades do administrador é resquício da abordagem científica que o Direito Tributário recebia na primeira metade do século passado, como ferramenta de proteção do Estado frente ao contribuinte e em prol da arrecadação. ${ }^{4}$ Ainda presente atualmente (mesmo que em menor medida), essa noção ignora a relevante vinculação jurídica material exigida pela Constituição para que sejam instituídas diferenciações entre os indivíduos. Com base nela, introduzem-se critérios eminentemente políticos na análise jurídica desses institutos, acabando por afastar a verificação da matéria pelo Poder Judiciário, supostamente vedado pelo princípio da separação dos poderes. Essa alegação desconhece que os benefícios fiscais devem se fundar em pressupostos objetivos, pois visam diretamente ao atingimento de interesses públicos e apenas indiretamente ao favorecimento de particulares. ${ }^{5}$

A despeito da concepção que se adota acerca dos benefícios fiscais, persiste o debate sobre o modo como os respectivos dispositivos devem ser interpretados, havendo posições dissonantes tanto na jurisprudência quanto na doutrina. Entretanto, o principal ponto de divergência reside no conteúdo prescritivo do artigo 111 do CTN. Via de regra, a expressão "interpreta-se literalmente" constante no referido dispositivo é tratada pela jurisprudência como sinônimo ou de interpretação estrita, ou restritiva, ou ainda como vedação de interpretação extensiva.

Essas diferentes acepções são encontradas em julgados de um mesmo tribunal. Tomando-se como exemplo posicionamentos do Superior Tribunal de Justiça, a respeito do artigo 111, é possível encontrar decisões que se coadunam com diferentes significados para a expressão "interpreta-se literalmente". Em um primeiro caso, o Tribunal analisou a aplicação de dedução de imposto de renda pessoa física para gastos com pensão alimentícia

\footnotetext{
${ }^{3}$ ULHÔA CANTO, Gilberto. "Legislação tributária, sua vigência, sua eficácia, sua aplicação, interpretação e integração". In Revista Forense, n. 267, p. 30.

${ }^{4}$ SERRANO, Carmelo Lozano. Exenciones tributarias y derechos adquiridos. Madrid: Tecnos, 1988. De igual modo: GODOI, Marciano Seabra de; SALIBA, Luciana Goulart Ferreira. "Interpretação e aplicação da lei tributária". In MACHADO, Hugo de Brito. Interpretação e aplicação da lei tributária. Fortaleza: Dialética/ICET, 2010.

${ }^{5}$ BORGES, José Souto Maior. "Interpretação da isenção no código tributário nacional (CTN)". In ELALI, André; MACHADO SEGUNDO, Hugo de Brito; TRENNEPOHL, Terence (Coord.). Direito Tributário: homenagem a Hugo de Brito Machado. São Paulo: Quartier Latin, 2011, p. 326.
} 
paga para filho maior de 24 anos por ordem judicial. Na oportunidade, decidiu que o recorrente não teria direito à dedução porque o artigo 111 do CTN "recomenda interpretação restritiva à legislação tributária". ${ }^{6}$ Em um segundo caso, o Tribunal analisou a aplicação de isenção do imposto de renda pessoa física sobre os proventos de aposentadoria e de reforma de portador de moléstia grave não elencada no rol da Lei no 7.713/88. No caso, decidiu ser “incabivel interpretação extensiva do aludido benefício à situação que não se enquadre no texto expresso da lei, em conformidade com o estatuído pelo art. 111, II, do CTN". 7 Em um terceiro caso, o mesmo Tribunal denegou o direito do contribuinte de ter benefício fiscal relativo ao ICMS com base em entendimento sumulado pelo próprio Tribunal de cláusula prevista no Acordo GATT. A Súmula determinava que "O bacalhau importado de país signatário do GATT é isento do ICMS", e o contribuinte pretendia o gozo do benefício para o salmão. Na oportunidade, o órgão entendeu que o salmão "não goza de isenção, benefício esse, de interpretação estrita, não há como se conferir a alforria fiscal (...) Interpretação literal que se impõe na defesa da ordem tributária (art. 111, CTN)". ${ }^{8}$

De modo semelhante do que ocorre no âmbito dos tribunais judiciais, as decisões administrativas também se mostram cambiantes sobre o conteúdo do artigo 111. Tomandose como exemplo julgados do Conselho Administrativo de Recursos Fiscais, verificam-se decisões que o tribunal aduz ser a literalidade o critério de interpretação intransponível dos dispositivos relativos à desoneração tributária, alegando que "impõe-se a interpretação restritiva na legislação que disponha sobre exclusão do crédito tributário". ${ }^{9}$ Ao mesmo tempo em que também se verificam decisões nas quais o tribunal se vale de interpretação teleológica, com base nos objetivos perquiridos pela norma desonerativa, para estabelecer que "o fato da interpretação da outorga de isenção ter de ser literal (artigo 111 do CTN) não implica a desconsideração de seu verdadeiro sentido. Se uma norma isentiva visa a incentivar a concessão de um benefício de cunho social, o que se impede é a sua concessão de forma individualizada ou discriminatória". ${ }^{10}$

\footnotetext{
${ }^{6}$ Superior Tribunal de Justiça, Segunda Turma, REsp 1.665.481, Relator Ministro Herman Benjamin, DJe 09.10.2017.

${ }^{7}$ Superior Tribunal de Justiça, Segunda Turma, Agravo Regimental no REsp 1.165.360, Relator Ministro Humberto Martins, DJe 22.08.2011.

${ }^{8}$ Superior Tribunal de Justiça, Primeira Turma, Agravo Regimental no AI 590.239, Relator Ministro Luiz Fux, DJe 28.05.2005.

${ }^{9}$ Conselho Administrativo de Recursos Fiscais, Processo no ${ }^{\circ}$ 16327.000137/2004-53, Acórdão publicado em 16.07.2018.

${ }^{10}$ Conselho Administrativo de Recursos Fiscais, Processo n ${ }^{\circ}$ 15504.725541/2012-92, Acórdão publicado em 02.05 .2016
} 
Importante reconhecer que a controvérsia presente nesses casos práticos se reporta a dispositivo de lei presente no ordenamento jurídico brasileiro desde 1966 e que, até os dias atuais, suscita dúvidas quanto à sua aplicação. Assim como a jurisprudência não parece encontrar consenso, a doutrina jurídico-tributária nacional possui representantes de variadas correntes interpretativas relativamente ao artigo 111 do CTN. A título ilustrativo, Bernardo Ribeiro de Moraes sustenta que, por conta do mencionado dispositivo, o intérprete "fica com a sua função delimitada pela letra da lei, sem poder ampliar nem restringir a norma jurídica, além de sua exata significação". ${ }^{11}$ José Souto Maior Borges aduz que "o dispositivo não prescreve que as isenções somente devem ser interpretadas literalmente. É ponto de partida. Não ponto terminal da exegese". ${ }^{12}$ Por sua vez, Renato Lopes Becho constata que o art. 111 “desorganiza a harmonia sistêmica do direito tributário" e, caso o Código Tributário Nacional venha a ser reformado, o melhor seria revogá-lo. ${ }^{13}$ Ao passo que, Luís Eduardo Schoueri, ao analisar aspectos históricos da edição do enunciado, percebeu que não se visava conferir restrição ao alcance dos dispositivos relativos a benefícios fiscais, isto é, "literalmente' significaria 'sem qualquer restrição". ${ }^{14}$

Tendo em vista a aparente dissonância jurisprudencial - tanto judicial quanto administrativa - e, sobretudo, a falta de consenso doutrinário sobre a interpretação de dispositivos que veiculam hipóteses de desoneração da carga tributária, a relevância do tema e a justificativa para o seu estudo restam demonstradas.

Para tanto, o presente estudo seguirá o seguinte plano de abordagem: o trabalho encontra-se dividido em duas partes maiores, que, por sua vez, subdividem-se em capítulos. A primeira parte cuida da definição de interpretação literal e de benefício fiscal. Sem que se tenha uma definição precisa desses dois institutos jurídicos é impossível a consecução de uma conclusão plausível para a hipótese central desse trabalho, que é a delimitação dos critérios que devem servir de parâmetro quando da interpretação dos dispositivos relativos a benefícios fiscais. O primeiro capítulo trata da definição de interpretação literal para o Direito, ele justifica-se pelo fato de que existe dispositivo expresso no Código Tributário Nacional que faz referência à interpretação literal, cujo conteúdo prescritivo não é entendido

\footnotetext{
${ }^{11}$ MORAES, Bernardo Ribeiro de. Compêndio de Direito Tributário. $2^{\circ}$ vol. $3^{\mathrm{a}}$ ed. Rio de Janeiro: Forense, 1997, p. 230.

${ }^{12}$ BORGES, José Souto Maior. "Interpretação da isenção no código tributário nacional (CTN)". In ELALI, André; MACHADO SEGUNDO, Hugo de Brito; TRENNEPOHL, Terence (Coord.). Direito Tributário: homenagem a Hugo de Brito Machado. São Paulo: Quartier Latin, 2011, p. 325.

${ }^{13}$ BECHO, Renato Lopes. Lições de Direito Tributário. $3^{\mathrm{a}}$ ed. São Paulo: Saraiva, 2015, p. 170.

${ }^{14}$ SCHOUERI, Luís Eduardo. Direito Tributário. $8^{a}$ ed. São Paulo: Saraiva, 2018, p. 815. 20
} 
de forma uníssona pelos tribunais nem pela doutrina. O segundo capítulo versa sobre a definição de benefício fiscal, ele justifica-se tanto porque a matéria a ser interpretada gera impactos no emprego dos argumentos interpretativos quanto porque é relevante para que se identifique quais são os dispositivos para os quais os parâmetros de interpretação traçados no trabalho serão válidos.

A segunda parte do presente estudo cuida da fixação dos critérios a serem verificados pelo intérprete e pelo aplicador quando da interpretação de dispositivos relativos a benefícios fiscais. O terceiro capítulo trata da relação entre a interpretação e o Direito Tributário brasileiro, ele justifica-se para identificar as normas jurídico-tributárias que exercem função eficacial interpretativa sobre a legislação tributária, sendo relevante para a futura delimitação dos critérios de interpretação para os benefícios fiscais. O quarto capítulo versa sobre a interpretação do artigo 111 do Código Tributário Nacional, ele justifica-se para definir tanto a matéria que o dispositivo visa a disciplinar quanto aos critérios de interpretação fixados por norma reconstruída a partir dele. O quinto capítulo trata da aplicação dos critérios de interpretação anteriormente identificados tendo em vista casos difíceis, ele justifica-se pelo fato de que nesses casos subsiste um entrechoque de resultados normativos que impactarão diretamente no âmbito de aplicação da norma desonerativa, levando-se em consideração, ainda, a atuação dos órgãos de julgamento. 


\section{CONCLUSÕES}

Este trabalho chegou à conclusão principal de que o ordenamento jurídico brasileiro possui normas que fixam parâmetros de interpretação dos dispositivos relativos a benefícios fiscais. Dentre essas normas, destacam-se os princípios da igualdade, da legalidade e da segurança jurídica, e o artigo 111 do Código Tributário Nacional. A aplicação em conjunto dessas normas estabelece os seguintes critérios de interpretação dos dispositivos relativos a benefícios fiscais: i) esses dispositivos devem ser interpretados com base em argumentos teleológicos, tendo em vista a necessidade de adequação entre a finalidade que lhes é subjacente e a Constituição; ii) no entanto, caso a interpretação literal se demonstre mais abrangente que a interpretação teleológica, a primeira deve prevalecer, funcionando como um marco de segurança jurídica para os contribuintes; e iii) as normas reconstruídas a partir desses dispositivos não podem sofrer integração analógica, por força do princípio da legalidade. A referida conclusão principal, entretanto, não subsiste autonomamente, na medida em que ela é suportada por uma série de outras conclusões menores que foram obtidas ao longo do trabalho e que serão aqui sumarizadas:

1. O vocábulo "interpretação" é ambíguo, podendo significar tanto a atividade de intepretação quanto o resultado desta atividade. No que se refere à atividade interpretativa, o referido vocábulo possui uma outra ambiguidade, pois pode significar tanto a atividade de atribuição de significado aos textos (interpretação stricto sensu) quanto a atividade de criação jurídica (interpretação em sentido amplo).

2. Dentre as correntes doutrinárias que explicam a atividade interpretativa, a corrente denominada mista ou cognitivista moderada foi a que se demonstrou mais adequada tendo em vista as premissas de Direito traçadas neste trabalho. Assim, a atividade interpretativa consiste na prática discursiva estruturada, que, com base no texto, racionaliza argumentos, técnicas e regras de prevalência para em alguns casos descrever o significado, e, em outros casos, adscrever um significado dentre os possíveis.

3. O sentido literal dos textos é objeto de estudos pela filosofia da linguagem, tendo o Direito se valido dos avanços conquistados naquela área do conhecimento para traçar perspectivas próprias sobre o sentido literal dos textos jurídicos. As correntes filosóficas dividem-se entre aqueles que sustentam a possibilidade de um significado literal (literalismo), advindo de uma análise acontextual, e aqueles que sustentam ser impossível a delimitação de um significado para um texto sem a investigação do contexto em que está 
inserido (antiliteralismo). No entanto, uma terceira vertente, denominada de literalismo moderado, sustenta que os textos podem ter um significado literal, sendo este apreensível pelos sentidos usuais dos termos e expressões e pela análise do co-texto, que é o microssistema que gira em torno do texto objeto da interpretação.

4. Para o Direito, a busca por um significado literal é disputado pela doutrina, que se divide entre várias acepções possíveis, dentre as quais: irreflexivo, abstrato, formal, linguístico, gramatical, imediato, óbvio, ordinário, patente, textual, próprio, semântico, semiótico, expresso, não-corretivo, acontextual, aparente e estrito. No entanto, é assente no Direito a conclusão de que há um sentido literal passível de reconstrução dos textos jurídicos.

5. Embora haja disputa em relação à definição de significado literal, é possível reconstruir da doutrina jurídica alguns elementos de encontro que levam à uma definição plausível de interpretação literal para o Direito. Destacam-se dois desses elementos: i) a intepretação literal para a doutrina jurídica está voltada a uma análise dos sentidos das palavras a partir de regras gramaticais (sintática e semântica); e ii) a interpretação literal leva em consideração um microssistema jurídico, composto por premissas jurídicas triviais (segurança jurídica, igualdade e justiça) e outros dispositivos diretamente conectados (geralmente do mesmo documento normativo). Tem-se, portanto, que a definição de interpretação literal para o direito é bastante próxima daquela empregada pela filosofia da linguagem, podendo ser assim resumida: interpretação literal é tanto a atividade quanto o resultado interpretativo que consiste no emprego do sentido usual dos termos e das expressões utilizadas no texto jurídico, analisados sob a perspectiva de seu co-texto.

6. Interpretação literal não se confunde com interpretação estrita e restritiva e, tampouco, se confunde com vedação à interpretação extensiva. A diferença marcante entre esses institutos é que, de um lado, interpretação literal é uma espécie de argumentação interpretativa ou o resultado do emprego dessa argumentação, enquanto as interpretações estrita, restrita e extensiva são conclusões acerca de comparações entre resultados interpretativos (geralmente, interpretação literal contraposta à interpretação teleológica).

7. No que se refere ao conceito de benefício fiscal, o trabalho chegou à conclusão de que ele possui uma definição ampla, no sentido de desoneração prévia da carga tributária, que, por sua vez, engloba tanto as obrigações principais quanto as obrigações acessórias. Para que seja constatada a existência de um benefício fiscal é necessário que o legislador ou administrador modifique o ordenamento jurídico no âmbito de sua competência tributária 
previamente exercida. Isto é, benefício fiscal não se confunde com imunidade, nãocompetência ou não-incidência em sentido estrito.

8. No que concerne às obrigações principais, os benefícios fiscais podem ser de várias espécies, sendo comumente classificados entre isenção total (isenção em sentido estrito, que bloqueia a incidência da norma de tributação por completo) e isenção parcial (que bloqueia parte da norma de tributação), esta última recebe várias denominações a depender do critério normativo sobre o qual incide (alíquota zero, redução de base de cálculo, redução de alíquota, dentre outros). Embora diga respeito a apenas um dos critérios normativos, é possível que as isenções parciais atinjam o mesmo efeito financeiro de zerar o montante a ser repassado aos cofres públicos. No que concerne às obrigações acessórias, estas reduzem os custos de conformidade que os contribuintes possuem para arcar com o cumprimento das obrigações principais. Geralmente são verificáveis na simplificação ou redução da entrega de documentos pelos contribuintes para as administrações tributárias.

9. Os benefícios fiscais são regulados por regime jurídico composto por uma série de normas do ordenamento. Dentre as quais, destacam-se: o princípio da legalidade, o princípio da anterioridade, o princípio da igualdade e o princípio da segurança jurídica.

10. Em relação ao princípio da igualdade, este exerce uma função eficacial interpretativa relevante em relação aos dispositivos que versam sobre benefícios fiscais. Isto porque, a igualdade exige que os benefícios fiscais encontrem finalidade fundamentada em objetivo constitucional, sob pena de instaurar estado de discriminação entre particulares. A relação dos benefícios fiscais com a igualdade decorre de uma característica própria dos estados de sujeição que os benefícios fiscais impõem aos particulares. Uma vez existente um benefício fiscal, necessariamente indivíduos serão tratados de forma diferente, uns recebendo desoneração em sua carga tributária e outros não. Logo, o exame detido da igualdade é medida importante no tratamento dessas normas.

11. No que tange à interpretação da legislação tributária, chegou-se à conclusão de que não há uma interpretação própria do Direito Tributário, no sentido de que não há argumentos, técnicas, regras de prevalência, nem enunciados e significados interpretativos exclusivos da matéria tributária. Há, contudo, uma interpretação necessariamente tributária, no sentido de que, os diferenciais do Sistema Tributário Nacional requerem a observância de algumas especificidades na interpretação da legislação tributária.

12. Do ponto de vista da interpretação como atividade ou processo, deve-se observar: i) necessidade de emprego da interpretação conforme a Constituição em sua função 
negativa para descartar significados contrários aos princípios gerais de Direito e aos princípios tributários presentes na Constituição; ii) vedação à argumentação consequencialista; iii) vedação à argumentação econômica; e iv) necessidade de aplicação de regras de prevalência decorrentes da função eficacial interpretativa dos princípios do Estado de Direito, da separação dos poderes, da segurança jurídica, da legalidade e da igualdade. E, do ponto de vista da interpretação como produto ou resultado, deve-se observar a necessidade de os significados atribuídos aos textos serem compatíveis com a Constituição.

13. A igualdade e a segurança jurídica exercem força eficacial interpretativa sobre a legislação tributária, o que pode levar a resultados interpretativos diversos. Ademais, a respeito da interpretação dos dispositivos que versam sobre benefícios fiscais, desponta o artigo 111 do Código Tributário Nacional, que utiliza a expressão "interpreta-se literalmente". Assim, a definição do conteúdo prescritivo do referido dispositivo se impõe, tanto porque a doutrina e a jurisprudência adotam posições cambiantes a respeito desse conteúdo, quanto porque ele parece ser dissonante com as normas constitucionais. Com base no emprego dos métodos literal, genético e sistemático para a interpretação do dispositivo, chegou-se às seguintes conclusões.

14. Em primeiro lugar, o método literal é incompatível com a Constituição porque resultaria em norma que fixaria somente a interpretação literal para os dispositivos relativos aos benefícios fiscais, vedando a aplicação de outros métodos mesmo que com argumentação fundamentada na igualdade. A incompatibilidade deste método com a Constituição decorre da função eficacial interpretativa que o princípio da igualdade exerce sobre os benefícios fiscais, uma vez que estes instauram ambiente de diferenciação entre os contribuintes. Assim, a investigação da finalidade dessas normas é uma imposição constitucional que não pode ser limitada pela interpretação exclusivamente literal.

15. Em segundo lugar, o método genético é compatível com a Constituição pois estabelece, de um lado, a prevalência da interpretação literal em proteção do contribuinte albergado pela literalidade, e de outro lado, veda a aplicação de integração analógica para extensão de benefício fiscal não previsto na legislação. A investigação dos trabalhos preparatórios do Código Tributário Nacional demonstra que a ratio legis do artigo 111 era a proteção do contribuinte para os casos em que este estivesse contemplado pela literalidade da norma que trata do benefício fiscal, mesmo que a teleologia infirme a aplicação do benefício para o caso em concreto. 
16. E, em terceiro lugar, o método sistemático corrobora as conclusões obtidas pelo emprego do método genético, ao mesmo tempo em que aduz que a norma reconstruída do artigo 111 não oferece qualquer tipo de vedação à interpretação teleológica, inclusive nos casos em que resulta em extensão do âmbito de aplicação do benefício fiscal. O método sistemático é responsável pela compatibilização do dispositivo com as normas constitucionais, em especial o princípio da igualdade.

17. A investigação da literalidade e da teleologia da norma relativa a benefício fiscal nem sempre serão compatíveis. Haverá casos em que ocorre entrechoque dos resultados interpretativos reconstruídos com base nessas argumentações, desafiando o órgão aplicador do Direito. Entretanto, não é possível reconstruir uma regra de prevalência taxativa sobre qual sentido normativo deverá ser aplicado, devendo ser considerado:

18. De um lado, quando a teleologia incluir mais casos do que a literalidade, a primeira deverá prevalecer. Esta conclusão se dá pela aplicação do princípio da igualdade. Ademais, como os benefícios fiscais se justificam nas finalidades constitucionais, as situações compatíveis com essas finalidades devem ser contempladas com a aplicação da regra desonerativa. Apesar de se admitir interpretação extensiva das regras desonerativas, o ordenamento, conforme dito anteriormente, veda a integração analógica dessas regras.

19. De outro lado, quando a literalidade abranger mais casos do que a teleologia, a primeira deverá prevalecer. Esta conclusão decorre da aplicação do artigo 111 do CTN que estabelece a literalidade como marco de segurança jurídica para os contribuintes. Esta conclusão é também suportada pela constatação de que a argumentação pela teleologia encontra fundamento da igualdade, no entanto este tipo de argumentação só protege ao contribuinte por ser direito fundamental. Em outras palavras, é vedado ao fisco argumentar no sentido de privilegiar a teleologia da norma com base na igualdade com o intuito de restringir o direito do contribuinte.

20. Por fim, essas normas reconstruídas a partir do ordenamento jurídico (em especial igualdade, legalidade, segurança jurídica e artigo 111 do CTN) não são peremptórias. Haverá casos extremos em que o postulado da razoabilidade ensejará em sua relativização com base em um apelo de justiça. Devendo, nesses casos, o aplicador estar diante de circunstâncias que favoreçam essa relativização e munido de argumentação robusta. 


\section{REFERÊNCIAS BIBLIOGRÁFICAS}

AARNIO, Aulis. Essays on the Doctrinal Study of Law. Dordrecht: Springer, 2011.

. Lo racional como razonable: um tratado sobre la justificación jurídica. Madrid: Centro de Estudios Políticos y Constitucionales, 1991.

. "Statutory interpretation in Finland". In MACCORMICK, Neil; SUMMERS, Robert

S. Interpreting statutes - a comparative study. Aldershot: Dartmouth, 1991.

AGUIAR, Luciana Ibiapina Lira. "Reflexões históricas sobre o artigo 111 do CTN: a escolha pela expressão 'literalmente' em oposição à expressão 'restritivamente'”. In Direito Tributário Atual, vol. 32, 2014, p. 245-255.

ALEXANDER, Larry. "All or nothing at all?". In Legal Rules and Legal Reasoning. Aldershot: Dartmouth, 2000.

ALHO NETO, João de Souza. “Coisa julgada vs. igualdade em matéria tributária: o conflito a partir da perspectiva da livre concorrência". In Revista Direito Tributário Atual, $\mathrm{n}^{\circ} 43$, 2019, p. 197-221.

ÁLVAREZ, Mónica Siota. Analogia e interpretación en el derecho tributario. Madrid: Marcial Pons, 2010.

AMARO, Luciano. Direito Tributário brasileiro. 12a ed. São Paulo: Saraiva, 2012.

AMAYA, Adolfo A. La interpretación de las leys tributarias. Buenos Aires: Arayú, 1954.

ATALIBA, Geraldo. Sistema Constitucional Tributário Brasileiro. São Paulo: RT, 1968.

ATIENZA, Manuel. Sobre la analogía en el derecho. Madrid: Civitas, 1986.

ÁVILA, Humberto. “Argumentação jurídica e a imunidade do livro eletrônico". In Revista da Faculdade de Direito da UFRGS, vol. 19, 2001, p. 157-180.

. "A separação dos poderes e as leis interpretativas modificativas de jurisprudência consolidada". In DERZI, Misabel Abreu Machado (Coord.). Separação de poderes e efetividade do sistema tributário. Belo Horizonte: Del Rey, 2010.

. "Benefícios fiscais inválidos e a legítima expectativa dos contribuintes". In Revista Internacional de Direito Tributário, no 5, 2006, p. 93-109.

. Competências Tributárias: um ensaio sobre a sua compatibilidade com as noções de tipo e conceito. São Paulo: Malheiros, 2018.

. Constituição, liberdade e interpretação. São Paulo: Malheiros, 2019.

. "Discurso de posse como professor titular". In Revista da Faculdade de Direito, vol. 110, 2015, p. 927-931. 
. "Eficácia do novo Código Civil na legislação tributária". In GRUPPENMACHER, Betina (Org.). Direito Tributário e o Novo Código Civil. São Paulo: Quartier Latin, 2004.

. "Estatuto do contribuinte: conteúdo e alcance". In Anais da XX Jornadas do ILADT

- Tema 1: Derechos humanos y tributación, Salvador, 2000, p. 575-605.

- "Função da Ciência do Direito Tributário: do formalismo epistemológico ao estruturalismo argumentativo". In Direito tributário atual, vol. 29, 2013, p. 181-204.

. "Interpretación de las leyes". In MATUS, Jean Pierre (Coord.). Beccaria 250 años después dei delitti e delle pene. Montevidéu; Buenos Aires: Editorial B de F, 2011.

. "Limites à tributação com base na solidariedade social". In GRECO, Marco Aurélio; GODOI, Marciano Seabra. (Coord.). Solidariedade Social e Tributação. São Paulo: Dialética, 2005.

. Sistema Constitucional Tributário. $5^{\mathrm{a}}$ ed. São Paulo: Saraiva, 2012.

. Teoria da Igualdade Tributária. $3^{\text {a }}$ ed. São Paulo: Malheiros, 2015.

. Teoria da Segurança Jurídica. $5^{\text {a }}$ ed. São Paulo: Malheiros, 2019.

. Teoria dos Princípios: da definição à aplicação dos princípios jurídicos. $19^{\mathrm{a}}$ ed. São Paulo: Malheiros, 2019.

BALEEIRO, Aliomar. Direito Tributário brasileiro. 13 ${ }^{\mathrm{a}}$ ed. Rio de Janeiro: Forense, 2015.

BANDEIRA DE MELLO, Celso Antônio. O conteúdo jurídico do princípio da igualdade. $3^{\mathrm{a}}$ ed. $25^{\mathrm{a}}$ tir. São Paulo: Malheiros, 2017.

BANKOWSKI, Zenon; MACCORMICK, D. Neil. "Statutory interpretation in United Kingdom". In MACCORMICK, Neil; SUMMERS, Robert S. Interpreting statutes $-a$ comparative study. Aldershot: Dartmouth, 1991.

BARAK, Aharon. Purposive interpretation in law. Trad. Sari Bashi. Princeton: Princeton University Press, 2005.

BARBERIS, Mauro. Una filosofia del diritto per lo stato constituzionale. Torino: G. Giappichelli Editore, 2017.

BECHO, Renato Lopes. "Considerações sobre a interpretação literal e o art. 111 do CTN". In Revista Dialética de Direito Tributário, n. 175, p. 161-178.

BECKER, Alfredo Augusto. Teoria Geral do Direito Tributário. São Paulo: Saraiva, 1963.

BOBBIO, Norberto. “Analogia”. In Saggi sulla scienza giuridica. Torino: G. Giappichelli Editore, 2011. 
BORGES, José Souto Maior. "Interpretação da isenção no código tributário nacional (CTN)". In ELALI, André; MACHADO SEGUNDO, Hugo de Brito; TRENNEPOHL, Terence (Coord.). Direito Tributário: homenagem a Hugo de Brito Machado. São Paulo: Quartier Latin, 2011.

. Teoria geral da isenção tributária. $3^{\mathrm{a}}$ ed. São Paulo: Malheiros, 2001.

BRANDÃO, Antônio José. "A interpretação das leis fiscais". In Revista de Direito Administrativo, vol. 33, 1953, p. 67-83.

BUSTAMANTE, Thomas; ALVES, Henrique Napoleão. "A interpretação literal no Direito Tributário brasileiro: uma proposta de interpretação para o artigo 111 do CTN". In ÁVILA, Humberto. Fundamentos de Direito Tributário. Madrid: Marcial Pons, 2012.

CAMPOS, Antonio J. Franco de. "Interpretação e integração da legislação tributária". In MARTINS, Ives Gandra da Silva (Org.). Comentários ao Código Tributário Nacional. Vol. 2. 5 ed. São Paulo: Saraiva, 2008.

CARRAZZA, Roque Antonio. Curso de Direito Constitucional Tributário. 32a ed. São Paulo: Malheiros, 2015.

. ICMS. 16ª ed. São Paulo: Malheiros, 2012.

. Imposto sobre a renda: perfil constitucional e temas específicos. São Paulo: Malheiros, 2005.

_ . “O princípio da igualdade”. In Justitia, vol. 90, p. 337-341.

CARVALHO, Paulo de Barros. Curso de Direito Tributário. $27^{\mathrm{a}}$ ed. São Paulo: Saraiva, 2016.

Direito Tributário, linguagem e método. São Paulo: Noeses, 2008.

CASÁS, José Oswaldo. Derechos y garantías constitucionales del contribuyente: a partir del principio de reserva de ley tributaria. Buenos Aires: AdHoc, 2005.

CHEVALLIER, Jacques. "Postface". In GUGLIELMI, Gilles J. (Ed.). La faveur et le droit. Paris: PUF, 2009.

CHIASSONI, Pierluigi. Técnicas de interpretación jurídica: brevario para juristas. Trad. Pau Luque Sánchez e Maribel Narváez Mora. Madrid: Marcial Pons, 2011.

COÊLHO, Sacha Calmon Navarro. Curso de Direito Tributário Brasileiro. $13^{\mathrm{a}}$ ed. Rio de Janeiro: Forense, 2014.

. Teoria geral do tributo, da interpretação e da exoneração tributária. $3^{\mathrm{a}}$ ed. São Paulo: Dialética, 2003.

COTÉ, Pièrre-André. Interprétation des lois. $4^{\mathrm{a}}$ ed. Montreal: Thémis, 2009. 
DASCAL, Marcelo. “Defending literal meaning”. In Cognitive Science, n. 11, 1987, p. 259281.

DEDEURWAERDER, Gilles. Théorie de l'interprétation et droit fiscal. Paris: Dalloz, 2010.

DERZI, Misabel Abreu Machado. Direito Tributário, Direito Penal e tipo. São Paulo: RT, 1988.

. Nota de atualização. In BALEEIRO, Aliomar. Direito Tributário brasileiro. $13^{\mathrm{a}} \mathrm{ed}$. Rio de Janeiro: Forense, 2015.

; BREYNER, Frederico Menezes. "Princípio da legalidade e os custos de conformidade na instituição de deveres instrumentais". In SOUZA, Priscila de (Org); CARVALHO, Paulo de Barros (Coord.). Racionalização do sistema tributário. São Paulo: Noeses/IBET, 2017.

DIAS, Daniela Gueiros. "Analogia no Direito Tributário brasileiro". In Revista Direito Tributário Atual, n 42, 2019, p. 214-240.

Consequencialismo judicial no Direito Tributário brasileiro. 190f. Dissertação (Mestrado em Direito). Universidade de São Paulo, São Paulo, 2018.

ENGISCH, Karl. Introdução ao pensamento jurídico. $8^{\mathrm{a}}$ ed. Trad. J. Baptista Machado. Lisboa: Fundação Calouste Gulbenkian, 2001.

FALCÃO, Amílcar de Araújo. "Interpretação e integração da lei tributária”. In Revista de Direito Administrativo, vol. 40, 1955, p. 24-37.

. Fato gerador da obrigação tributária. $2^{\mathrm{a}}$ ed. São Paulo: RT, 1971.

Introdução ao Direito Tributário. $6^{\mathrm{a}}$ ed. Atual. Flavio Bauer Novelli. Rio de Janeiro: Forense, 1999.

FERRAZ JR., Tércio Sampaio. "Da compensação de prejuízos físcais ou da trava de 30\%". In Revista Fórum de Direito Tributário, no 60, 2012, p. 9-31.

. Introdução ao estudo do Direito: técnica, decisão, dominação. $6^{\mathrm{a}}$ ed. São Paulo: Atlas, 2011.

FERREIRO LAPATZA, José Juan. Direito Tributário: teoria geral do tributo. Barueri: Manole; Espanha: Marcial Pons, 2007.

FETERIS, Eveline. "The pragma-dialectical reconstruction of teleological-evaluative argumentation in complex structures of legal justification". In OSSA Conference Archive - University of Windsor, paper 39.

FREITAS, Juarez. A interpretação sistemática do Direito. $5^{a}$ ed. São Paulo: Malheiros, 2010. 
FOLLONI, André Parmo. “Algumas anotações sobre a interpretação do Direito”. In Raízes Jurídicas, vol. 4, 2008, p. 275-299.

; BONAT, Alan Luiz. "Incentivos fiscais e suas condições de validade: igualdade e proporcionalidade". In Cadernos do Programa de Pós-Graduação Direito/UFRGS, vol. $\mathrm{X}, \mathrm{n}^{\circ} 2,2015$, p. 341-362.

. "Capacidade contributiva e dever fundamental". In Revista Direito Tributário Atual, $\mathrm{n}^{\circ}$ 42, 2019, p. 484-508.

. Ciência do Direito Tributário no Brasil: crítica e perspectivas a partir de José Souto Maior Borges. São Paulo: Saraiva, 2013.

. “Isonomia na tributação extrafiscal”. In Revista Direito GV, no 19, 2014, p. 201-220.

FULGINITI, Bruno Capelli. Deduções no imposto de renda: fundamento normativo e controle jurisdicional. São Paulo: Quartier Latin, 2017.

GADAMER, Hans-Georg. Verdade e método I: traços fundamentais de uma hermenêutica filosófica. $6^{\mathrm{a}}$ ed. Trad. Flávio Paulo Meurer e Enio Paulo Giachini. Petrópolis: Vozes, 2004.

GIANFORMAGGIO, Letizia. Filosofia del diritto e ragionamento giuridico. Torino: G. Giappicheli Editore, 2008.

GIANNINI, Achille Donato. Instituzioni di diritto tribuario. Milano: Giuffrè, 1948.

GIBBS JR., Raymond W. "Marcelo Dascal and the literal meaning debates". In WRIGLEY, Michael B. (Ed.). Manuscrito Revista Internacional de Filosofia-Dialogue, Language, Rationality: Festschrift for Marcelo Dascal. Vol. XXV(2). Campinas: CLE/Unicamp, 2002.

GODOI, Marciano Seabra de; GIANETTI, Leonardo Varella. "Regime jurídico dos incentivos fiscais". In MACHADO, Hugo de Brito (Coord.). Regime jurídico dos incentivos fiscais. São Paulo: Malheiros/ICET, 2015.

; SALIBA, Luciana Goulart Ferreira. "Interpretação e aplicação da lei tributária". In MACHADO, Hugo de Brito. Interpretação e aplicação da lei tributária. Fortaleza: Dialética/ICET, 2010.

GRECO, Marco Aurélio. Planejamento Tributário. 3a ed. São Paulo: Dialética, 2011.

GUASTINI, Riccardo. Dalle fonti alle norme. Torino: G. Giappichelli Editore, 1990.

. "El realismo jurídico definido". Trad. Álvarez Núñes Vaquero. In NÚÑEZ, Álvaro (Coord.). Modelando la ciencia jurídica. Lima: Palestra Editores, 2014.

. “Interpretación y construcción jurídica”. In Isonomía, n. 43, 2015, p. 11-48. 
. Interpretar y argumentar. Trad. Silvina Álvarez Medina. Madrid: Centro de Estudios Políticos y Constitucionales, 2014.

. L 'interpretazione dei documenti normativi. Milano: Giuffrè, 2004.

. La sintassi del diritto. Torino: G. Giappicheli Editore, 2011.

. Le fonti del diritto e l'interpretazione. Milano: Giuffrè, 1993.

. "Production of rules by means of rules". In Rechtstheorie, no 17, 1986, p. 285-309.

GUIMARÃES, Carlos da Rocha. "Interpretação literal das isenções tributárias". In Associação Brasileira de Direito Financeiro. Proposições Tributárias. São Paulo: Resenha Tributária, 1975.

HARAŠIĆ, Žaklina. "More about teleological argumentation in law". In Pravni Vjesnik God, n. 31, 2015, p. 23-49.

JARACH, Dino. "Hermenêutica no Direito Tributário". In ATALIBA, Geraldo (Coord.). Interpretação no Direito Tributário. São Paulo: EDUC/Saraiva, 1975.

KELSEN, Hans. Teoria Pura do Direito. $8^{\mathrm{a}}$ ed. Trad. João Baptista Machado. São Paulo: Martins Fontes, 2009.

KLATT, Matthias (University of Graz). "Constitutional-Conform Interpretation". Conferência. In International dialogues in constitutional law. São Paulo: Universidade de São Paulo, 2019.

. Making the law explicit: the normativity of legal argumentation. Portland, EUA: Hart Publishing, 2008.

KRELL, Andreas J. "Entre desdém teórico e aprovação na prática: os métodos clássicos de interpretação jurídica”. In Revista Direito GV, n. 19, 2014, p. 295-320.

LAPORTA, Francisco J. El império de la ley: una visión actual. Madrid: Editorial Trotta, 2007.

LA TORRE, Massimo; PATTARO, Enrico; TARUFFO, Michele. "Statutory interpretation in Italy". In MACCORMICK, Neil; SUMMERS, Robert S. Interpreting statutes $-a$ comparative study. Aldershot: Dartmouth, 1991.

LARENZ, Karl. Metodologia da Ciência do Direito. $7^{\mathrm{a}}$ ed. Trad. José Lamego. Lisboa: Fundação Calouste Gulbenkian, 2014.

LEBEAU, Martin. De l'interprétation stricte des lois: essai de méthodologie. Paris: Defrénois Lextenso, 2012.

LEÃO, Martha Toribio. "Contributo para o estudo da extrafiscalidade: a importância da finalidade na identificação das normas tributárias extrafiscais". In Revista Direito Tributário Atual, n 34, 2015, p. 303-325. 
. Controle da extrafiscalidade. São Paulo: Quartier Latin/IBDT, 2015.

- O direito fundamental de economizar tributos: entre legalidade, liberdade e solidariedade. São Paulo: Malheiros, 2018.

LUNARDELLI, Pedro Guilherme Accorsi. Isenções tributárias. São Paulo: Dialética, 1999.

MACCORMICK, Neil. "On Legal Decisions and their Consequences: from Dewey to Dworkin”. In New York University Law Review, vol. 58, n² 2, 1983.

MACHADO, Brandão. "Prefácio". In HARTZ, Wilhelm. Interpretação da lei tributária: conteúdo e limites do critério econômico. Trad. Brandão Machado. São Paulo: Resenha Tributária, 1993.

MACHADO, Hugo de Brito. Comentários ao Código Tributário Nacional. Vol. II. $2^{\mathrm{a}}$ ed. São Paulo: Atlas, 2008.

_. Curso de Direito Tributário. 32a ed. São Paulo: Malheiros, 2011.

. "O regime jurídico dos incentivos fiscais". In MACHADO, Hugo de Brito (Coord.). Regime jurídico dos incentivos fiscais. São Paulo: Malheiros/ICET, 2015.

MAXIMILIANO, Carlos. Hermenêutica a aplicação do Direito. $20^{\mathrm{a}}$ ed. Rio de Janeiro: Forense, 2011.

MAZZARESE, Tecla. Interpretación literal: juristas y linguistas frente a frente. In DoxaCuadernos de Filosofia del Derecho, v. 23, 2000, p. 597-631.

MELIS, Giuseppe. L’interpretazione nel Diritto Tributario. Milano: CEDAM, 2003.

MILEO FILHO, Francisco Sávio Fernandez. "Os custos de conformidade em contraposição à função e à importância das obrigações acessórias". In Revista de Fórum de Direito Financeiro e Econômico, ano 08, n ${ }^{\circ} 15,2019$, p. 41-65.

MINISTÉRIO DA FAZENDA. Trabalhos da Comissão Especial do Código Tributário Nacional. Rio de Janeiro, 1954.

MORAES, Bernardo Ribeiro de. Compêndio de Direito Tributário. $2^{\circ}$ vol. $3^{\mathrm{a}}$ ed. Rio de Janeiro: Forense, 1997.

NABAIS, José Casalta. "Solidariedade Fiscal, Cidadania e Direito Fiscal". In: GRECO, Marco Aurélio; GODOI, Marciano Seabra. (Coord). Solidariedade Social e Tributação. São Paulo: Dialética, 2005.

NASCIMENTO, Carlos Valder do. Direito Tributário IV: interpretação, obrigação e crédito tributário. Ilhéus: Editus, 2016.

. "Interpretação no Direito Tributário". In NASCIMENTO, Carlos Valder do (Org.). Estudos de Direito Tributário 1: interpretação no Direito Tributário. São Paulo: RT, 1989. 
NOGUEIRA, Ruy Barbosa. Curso de Direito Tributário. 13ª ed. São Paulo: Saraiva, 1994.

. "Interpretação e integração da legislação tributária". In NASCIMENTO, Carlos Valder do (Org.). Estudos de Direito Tributário 1: interpretação no Direito Tributário. São Paulo: RT, 1989.

Interpretação e integração da legislação tributária. São Paulo: IBDT/Resenha Tributária, 1975.

PECZENIK, Aleksander. On law and reason. $2^{\mathrm{a}}$ ed. Holanda: Springer Netherlands, 2008.

; BERGHOLZ, Gunnar. "Statutory interpretation in Sweden". In MACCORMICK, Neil; SUMMERS, Robert S. Interpreting statutes - a comparative study. Aldershot: Dartmouth, 1991.

PLUTARCO, Hugo Mendes; GICO JR., Ivo Teixeira; VALADÃO, Marcos Aurélio Pereira. "O custo social das obrigações tributárias acessórias". In Economic analysis of law review, vol. 3, no 2, 2012, p. 338-353.

POGGI, Francesca. "Significado literal: una noción problemática". In Doxa-Cuadernos de Filosofia del Derecho, v. 30, 2007, p. 617-634.

."The myth of literal meaning in legal interpretation". In Analisi e Diritto, v. 2013, p. 313-335.

POSTEMA, Gerald J. "Objectivity fit for law”. In LEITER, Brian (Ed.) Objectivity in Law and Morals - Cambridge Studies in Philosophy and Law. Cambridge, UK: Cambridge University Press, 2001.

PRESA, María Concepción Gimeno. "La interpretación literal de la ley". In Anuario de filosofía del derecho, n. 20, 2003, p. 131-150.

RATTI, Giovanni Battista. Sistema giuridico e sistemazione del diritto. Torino: G. Giappichelli Editore, 2008.

Studi sulla logica del diritto e della scienza giuridica. Madrid: Marcial Pons, 2013.

RÉGNIER, João Roberto Santos. A norma de isenção tributária. São Paulo: RT, 1975.

RIBAS, Pedro Henrique Garzon. Negócio jurídico indireto: definição e sua (in)aplicabilidade em matéria tributária. 147f. Dissertação (Mestrado em Direito). Universidade de São Paulo, São Paulo, 2019.

RIBEIRO, Maria de Fátima. "Legislação tributária - arts. 109 a 111”. In NASCIMENTO, Carlos Valder do; PORTELLA, André. Comentários ao Código Tributário Nacional lei $n^{o}$ 5.172, de 25.10.1966. $7^{\mathrm{a}}$ ed. Rio de Janeiro: Forense, 2008.

RIBEIRO, Ricardo Lodi. Justiça, interpretação e elisão tributária. Rio de Janeiro: Lumen Juris, 2003. 
SAVIGNY, Friedrich Karl von. Metodologia jurídica. Trad. Hebe A. M. Caletti Marengo. Campinas: Edicamp, 2001.

SCAFF, Fernando Facury; SILVEIRA, Alexandre Coutinho da. "Incentivos fiscais na federação brasileira". In MACHADO, Hugo de Brito (Coord.). Regime jurídico dos incentivos fiscais. São Paulo: Malheiros/ICET, 2015.

SCHAUER, Frederick. "The interpretation of rules". In Playing by the rules: a philosophical examination of rule-based decision-making in law and in life. Nova York: Oxford University Press, 2002.

. "The interpretation of statutes". In Thinking like a lawyer: a new introduction to legal reasoning. Cambridge, EUA; Londres: Harvard University Press, 2009.

SCHOUERI, Luís Eduardo. Direito Tributário. $8^{\text {a }}$ ed. São Paulo: Saraiva, 2018. 2005

Normas tributárias indutoras e intervenção econômica. Rio de Janeiro: Forense, .Planejamento tributário e garantias dos contribuintes: entre a norma geral antielisão portuguesa e seus paralelos brasileiros". In ALMEIDA, Daniel Freire e; GOMES, Fábio Luiz; CATARINO, João Ricardo (Org.). Garantias dos contribuintes no sistema tributário: homenagem a Diogo Leite de Campos. São Paulo: Saraiva, 2012.

. "Prefácio". In LEÃO, Martha Toribio. Controle da extrafiscalidade. São Paulo: Quartier Latin/IBDT, 2015.

. "Prefácio". In VIEIRA DA ROCHA, Paulo Victor. Teoria dos direitos fundamentais em matéria tributária. São Paulo: Quartier Latin, 2017.

SERRANO, Carmelo Lozano. Exenciones tributarias y derechos adquiridos. Madrid: Tecnos, 1988.

SESMA, Victoria Iturralde. Interpretación literal y significado convencional: uma reflexión sobre los limites de la interpretación jurídica. Madrid: Marcial Pons, 2014.

SOUSA, Rubens Gomes de. Compêndio de legislação tributária. São Paulo: Resenha Tributária, 1975.

. "Normas de interpretação no Código Tributário Nacional". In ATALIBA, Geraldo (Coord.). Interpretação no Direito Tributário. São Paulo: EDUC/Saraiva, 1975.

. "Relatório". In MINISTÉRIO DA FAZENDA. Trabalhos da Comissão Especial do Código Tributário Nacional. Rio de Janeiro, 1954.

TESAURO, Francesco. Instituições de Direito Tributário. Trad. Fernando Aurelio Zivelti e Laura Fiore Ferreira. São Paulo: IBDT, 2017.

TORRES, Ricardo Lobo. Normas de interpretação e integração do Direito Tributário. $4^{\mathrm{a}}$ ed. Rio de Janeiro: Renovar, 2006. 
TROPER, Michel; GRZEGORCZYK, Christophe; GARDIES, Jean-Louis. "Statutory interpretation in France”. In MACCORMICK, Neil; SUMMERS, Robert S. Interpreting statutes - a comparative study. Aldershot: Dartmouth, 1991.

TROTABAS, Louis. “A interpretação das leis fiscais”. In Revista de Direito Administrativo, vol. 1, n. 1, 1945, p. 38-47.

ULHÔA CANTO, Gilberto. "Legislação tributária, sua vigência, sua eficácia, sua aplicação, interpretação e integração". In Revista Forense, no 267.

VALCÁRCEL, Ernesto Lejeune. "O princípio da igualdade". In FERRAZ, Roberto (Coord.). Princípios e limites da tributação 2: os princípios da Ordem Econômica e a Tributação. São Paulo: Quartier Latin, 2009.

VANONI, Ezio. Natureza e interpretação das leis tributárias. Trad. Rubens Gomes de Sousa. Rio de Janeiro: Edições Financeiras, 1932.

VERNENGO, Roberto J. La interpretacion literal de la ley. $2^{\mathrm{a}}$ ed. Buenos Aires: AbeledoPerrot, 1994.

VIEIRA DA ROCHA, Paulo Victor. Teoria dos direitos fundamentais em matéria tributária. São Paulo: Quartier Latin, 2017.

WESTEN, Peter. Speaking of equality: an analysis of the rethorical force of 'equality' in moral and legal discourse. Princeton, EUA: Princeton University Press, 1990.

WRÓBLEWSKI, Jerzy. "Statutory interpretation in Poland". In MACCORMICK, Neil; SUMMERS, Robert S. Interpreting statutes - a comparative study. Aldershot: Dartmouth, 1991.

ZULETA-PUCEIRO, Enrique. "Statutory interpretation in Argentina". In MACCORMICK, Neil; SUMMERS, Robert S. Interpreting statutes - a comparative study. Aldershot: Dartmouth, 1991. 